\begin{tabular}{|c|c|c|}
\hline 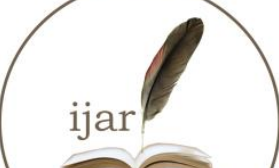 & $\begin{array}{l}\text { Journal Homepage: }-\underline{w w w . j o u r n a l i j a r . c o m} \\
\text { NNTERNATIONAL JOURNAL OF } \\
\text { ADVANCED RESEARCH (IJAR) }\end{array}$ & $\begin{array}{l}\text { INTERNATIONAL JOURNAL OF } \\
\text { ADVINCED RESEARCH IIJAR }\end{array}$ \\
\hline ISSN & $\begin{array}{l}\text { Article DOI: 10.21474/IJAR01/2943 } \\
\text { DOI URL: http://dx.doi.org/10.21474/IJAR01/2943 }\end{array}$ & \\
\hline
\end{tabular}

RESEARCH ARTICLE

\title{
AWARENESS OF ANTENATAL CARE IMPORTANCE AMONG SAUDI PREGNANT WOMEN IN
} MADINA.

Jehan M. Al hazmi ${ }^{1}$,Hatem M. Habib ${ }^{2}$, Somayah H. Sebeih ${ }^{2}$, Mohammed I. Khan ${ }^{2}$,Sara A. Elmaghrabi ${ }^{3}$, ReemJ.Tharwat ${ }^{3}$, SafanahS.Alshinqity ${ }^{2}$, Afaf M.Aljohani ${ }^{2}$ and Nada H. Mahmoud ${ }^{3}$.

1. OB/GYN Consultant, MMCH.

2. Medical intern, Taibah University.

3. Medical student, Taibah University.

\section{Manuscript Info}

(.........................

Manuscript History

Received: 25 November 2016

Final Accepted: 27 December 2016

Published: January 2017

Key words:-

Antenatal, Care, Pregnancy, Awareness,

Prevalence

\section{Abstract}

Introduction:Antenatal Care is care before birth and includes education, screening, counseling, treatment, monitoring and promoting the well-being of the mother and fetus. Its importance cannot be overstated for both.

Objective: To assess the awareness of antenatal care importance among pregnant women attending antenatal care clinics in Madina, Saudi Arabia.

Methodology: A cross-sectional study carried on (1617) women who attended Maternity and Children's Hospital and National Guard Hospital in Madina during the period from August to September 2016. The data were collected through face to face interview and use of questionnaire format.

Results: A total of 1617 women were selected in the study, $74.7 \%$ of the participant's ages were between 20-34 years old. Most of them had a university degree with percentage of $40 \% .80 .9 \%$ started following up at first or second trimester and $80.1 \%$ were following up their pregnancies consistently and regularly. $89.7 \%$ believed in the importance of antenatal care visits. $89 \%$ believed that the use complementary supplements during pregnancy can prevent some problems.

Conclusion: The education has been a great role in the interest of mothers in Antenatal care. Most of women have no diseases, and they believe that the use of complementary grain during pregnancy reduces the incidence of some of the problems related to pregnancy. More than half of women have a good awareness about knowledge of the importance of the first visit and the importance of continued follow-up in the same place. 


\section{Objectives: - \\ General objectives: -}

To assess the awareness of antenatal care importance among Saudi pregnant women attending ANC in Madina, Saudi Arabia

\section{Specific objectives: -}

1. To determine the role of mothers' education in antenatal care awareness.

2. To evaluate the knowledge about the importance of following up the whole period of pregnancy.

3. To assess the awareness of booking and its role in increasing the quality of care.

4. To inspect the effect of socioeconomic status on adherence to antenatal care.

5. To assess the awareness of taking specific supplements during pregnancy. e.g. folic acid.

\section{Introduction: -}

Antenatal Care (ANC) is "care before birth" and includes education, screening, counseling, treatment, monitoring and promoting the well-being of the mother and fetus. ${ }^{1}$ ANC is based on providing women and their families appropriate advices and information which may help them to be in a good health during pregnancy, delivery, and postnatal recovery. ${ }^{2}$ Also, providing mothers with appropriate supplements such as folic acid and vitamins that needed during pregnancy. ${ }^{3}$ In addition, providing care of newborn, promotion of early, exclusive breastfeeding, and assistance with family planning in order to improve pregnancy outcomes. To achieve the full life-saving potential that ANC promises for women and babies, four visits providing essential evidence based interventions a package often called focused antenatal care are required.Good caring during pregnancy is so important for the health of the mother and the development of the unborn baby, it links the woman and her family with a formal health system which will increase the chance of using a skilled attendant particularly at birth and contributes to well health through the life cycle. ${ }^{2}$ At any health care delivery system, Antenatal care is considered as a back bone of obstetrical services, it is substantial for health of pregnant women and it is the way in which maternal and fetal complications are determined and managed. ${ }^{3}$ Roughly, a thousand mothers all around the world die daily due to pregnancy and delivery related causes, ${ }^{4}$ which resemble $25 \%$ of maternal deaths according to World Health Organization. Although, maternal mortality rates in the past 25 years has decreased by about $44 \%$, it is still considered by WHO to be intolerably immense. The vast majority of these fatalities take place in low-resource settings, and hence preventable in a great measure. This matter of concern, therefore, was a first priority in The Millenium Development Goals (MDGs) acknowledged by the international community in 2000 which obligate the medical community globally to promote maternal health as one of their recommendations. ${ }^{5}$ Beside family planning, essential obstetric care, and safe delivery, antenatal care as one of the pillars of Safe Motherhood Initiative was encouraged by health providers as studies have proven that it can effectively curtail maternal morbidity and mortality ${ }^{6.7}$ Pregnant women in developed countries appreciate the role of antenatal care and they consider it full-fledged and accredited. On the other hand, its role in the perspectives of pregnant women in developing countries is debatable, thus, poor attendance is noted. ${ }^{3}$ Shalash\& Mohammed, 2012 stated that the vulnerability to diseases and death during pregnancy are decidedly higher among women who do not follow up in antenatal care clinics in contrast to women who do so. ${ }^{7}$ Furthermore, continuity of antenatal care in reachable and high quality clinics prevent problems and lessen deaths during pregnancy. ${ }^{2}$ Unsurprisingly, this would justify that developing countries have the largest share of maternal mortality which is $99 \% .{ }^{8}$ In our region, resolving the causes of lacking adherence to antenatal care has become an urgent demand since average number of ANC visits has dropped to the lower limit. ${ }^{9}$ The reason of poor antenatal care attendance is undoubtedly multifactorial, with factors having important roles linked to health providers, pregnant women themselves, and other elements. A study was conducted to assess the ANC performance of physicians in Madina, Saudi Arabia revealed that overall performance was fair to low, which is definitely unfavorable and does not live up to WHO expectations. Faulty application of antenatal care programs, prolonged waiting time, number of facilities, dissatisfaction of women toward doctors' attitude or their feedback, and other caregivers related dilemmas facing pregnant women indicate that antenatal care have rarely been subjected to assessment. ${ }^{10}$ Regarding pregnant women, they have many variables can influence attendance including educational level, socioeconomic status, and most importantly level of awareness of antenatal care importance which considered as a key factor to determine commitment to ANC visits. ${ }^{11}$ Women also can encounter various obstacles along the lines of transportation issues or that permission by the husband is not gained, a companion is not available to attend with her to the clinic, and other external troubles as might be cultural or traditional conflicts that she may face. ${ }^{12} \mathrm{Al}$ Otaiby et al., 2013 established a study that was one of the few of its kind in Riyadh, Saudi Arabia regarding awareness and recognition of antenatal care and they reported that antenatal knowledge scores were below average 
with no difference regarding age or literacy level among this population. ${ }^{13}$ Due to the scarcity of researches about the awareness of ANC in Saudi Arabia, we need more studies in different cities to assess the level of knowledge and awareness among pregnant women in our population in order to know to what extent should health authority raise public awareness of this issue.Our study aims to assess the awareness of antenatal care importance among Saudi pregnant women in Madina, Saudi Arabia and Find out the relationship between pregnant woman's knowledge with certain variables; age, educational level, socioeconomic status, gravidity, parity and number of prenatal care visits.

\section{Methodology: - \\ Study design: -}

This is a cross-sectional study which was conducted through a random sampling. The population was pregnant women mainly from Madina region in Saudi Arabia during August and September 2016. The aim of this study is to assess the awareness of antenatal care importance among Saudi pregnant women attending Antenatal clinics of several hospitals including $\mathrm{MMCH}$ and $\mathrm{MNGH}$, and to explore the factors that influence antenatal care attendance.All recruited subjects of this study were actively involved in attending ANC clinics. Subjects who were too sick to participate and non-Saudi women have been excluded from the study analysis. A pre-designed structured Arabic and English languages questionnaires were used in this cross-sectional survey through face to face interview. The used questionnaires were formulated to include demographic aspects, clinical features, nutritional, medical, obstetric and psycho-social history. The questionnaires include 39 questions, discussing various aspects in the subject's socioeconomic, educational, medical and psychological life. The questionnaires' items were designed and written to suit the tradition and the Islamic culture of the Holly Madina City.The questionnaires with missing data more than 50\% were excluded from the study analysis. The final study sample size was 1617 pregnant women.Approval was taken from the ethics committee at Maternity and Children Hospital in Madina, Saudi Arabia. Ethical consideration was considered to avoid physical or emotional harm in the study questionnaire. The confidentiality and privacy of the collected data were ensured through the use of anonymous questionnaire and during data entry and analysis. People were provided with information on the study aims and methods and each one of them has signed an informed consent to participate in this study.

\section{Statistical analysis: -}

The collected data were analyzed using statistical analysis system (SAS). Data from the questionnaire has been entered as numerical or categorical, as appropriate. Two types of statistics have been done:

1. Descriptive statistics; where quantitative data was shown as mean \pm S.D for women in each group, and qualitative data was expressed as frequency and percent which plays the proportion of participants who are represented within each category.

2. Analytical statistics: where Chi- square test between qualitative variables. Also, unpaired women's t-test was used as a test of significance for comparison between two arithmetic means of two different groups. The level of statistical significance was defined as $\mathrm{P} \leq 0.05$.

\section{Results: -}

This section of the study gives descriptive analysis through the repeat tables and the diagrams for the participants' answers on all the questionnaire questions, and then it analyzes and clarifies the most important statistical analysis obtained to achieve the study objectives.

\section{Population \& Sample of the Study: -}

The population was all pregnant women mainly from Madina region in Saudi Arabia during August and September 2016, a random sample of (1617) woman was selected, and table (1) shows their properties according to their personal information: 
Table 1:- The participants' personal data $(n=1617)$.

\begin{tabular}{|c|c|c|c|c|}
\hline \multicolumn{2}{|l|}{ Personal Data } & \# & $\%$ & $P$-value \\
\hline \multirow[t]{5}{*}{ Age } & Less than 20 & 44 & 2.7 & \multirow[t]{5}{*}{$0.00 * *$} \\
\hline & Between $20-25$ & 445 & 27.5 & \\
\hline & Between $26-34$ & 764 & 47.2 & \\
\hline & Between $35-40$ & 320 & 19.8 & \\
\hline & Above 40 & 44 & 2.7 & \\
\hline \multirow[t]{5}{*}{ Weight $(\mathrm{kg})$} & Less than 50 & 85 & 5.3 & \multirow[t]{5}{*}{$0.00 * *$} \\
\hline & $50-70$ & 865 & 53.5 & \\
\hline & $71-90$ & 536 & 33.1 & \\
\hline & $91-110$ & 99 & 6.1 & \\
\hline & More than 110 & 32 & 2.0 & \\
\hline \multirow[t]{3}{*}{ Height $(\mathrm{cm})$} & Less than 160 & 926 & 57.3 & \multirow[t]{3}{*}{$0.00 * *$} \\
\hline & $160-170$ & 671 & 41.5 & \\
\hline & More than 170 & 20 & 1.2 & \\
\hline \multirow[t]{2}{*}{ Residency } & Urban & 1391 & 86.0 & \multirow[t]{2}{*}{$0.00 * *$} \\
\hline & Rural & 226 & 14.0 & \\
\hline \multirow[t]{6}{*}{ Level of education } & Illiterate & 83 & 5.1 & \multirow[t]{6}{*}{$0.00 * *$} \\
\hline & Primary school & 160 & 9.9 & \\
\hline & Intermediate school & 171 & 10.6 & \\
\hline & High school & 486 & 30.1 & \\
\hline & College & 647 & 40.0 & \\
\hline & Higher education & 70 & 4.3 & \\
\hline \multirow[t]{6}{*}{ Husband's education } & Illiterate & 40 & 2.5 & \multirow[t]{6}{*}{$0.00 * *$} \\
\hline & Primary school & 107 & 6.6 & \\
\hline & Intermediate school & 141 & 8.7 & \\
\hline & High school & 578 & 35.7 & \\
\hline & College & 678 & 41.9 & \\
\hline & Higher education & 73 & 4.5 & \\
\hline \multirow[t]{3}{*}{ Income of household } & Excellent $(>10000)$ & 331 & 20.5 & \multirow[t]{3}{*}{$0.00 * *$} \\
\hline & Average (5000 10000) & 921 & 57.0 & \\
\hline & Below average $(<5000)$ & 365 & 22.6 & \\
\hline
\end{tabular}

Chi-squared test: $*$ Significant at $0.05 \quad * *$ Significant at 0.01

It is clear from the previous table that $47.2 \%$ of the participants' ages were between (26-34) years old, while $27.5 \%$ of them were between (20 -25) years old, $19.8 \%$ of them were between (35-40) years old, $2.7 \%$ of them were less than (20) years old, and the same percentage for those who were more than (40) years old. And their distribution according to their weight, $53.5 \%$ of the sample members had their weights between $(50-70) \mathrm{kg}$, while $33.1 \%$ of them had their weights between (71-90) kg. And according to their lengths the distribution was as follows, $57.3 \%$ of them were less than (160) cm long, while $41.5 \%$ were between $(160-170) \mathrm{cm}$ long, and $1.2 \%$ of them were more than (170) $\mathrm{cm}$ long. And when the participants were asked about their residence place, $86 \%$ said that they were living in Madina, while $14 \%$ of them were living in villages. When the participants were asked about their educational level; $40 \%$ of them had university degree, while $30.1 \%$ of them high school certificates. And the distribution according to their husbands' educational levels; $41.9 \%$ of them had university degree, while $35.7 \%$ of them had secondary school certificates. And finally, their distribution according to their monthly income; $20.5 \%$ of them had their income more than (10000) riyal, while 57\% of them had their income between (5000-10000) riyal, and $22.6 \%$ of them had a monthly income less than (5000) riyal. 
The next diagram concludes the previous results: -

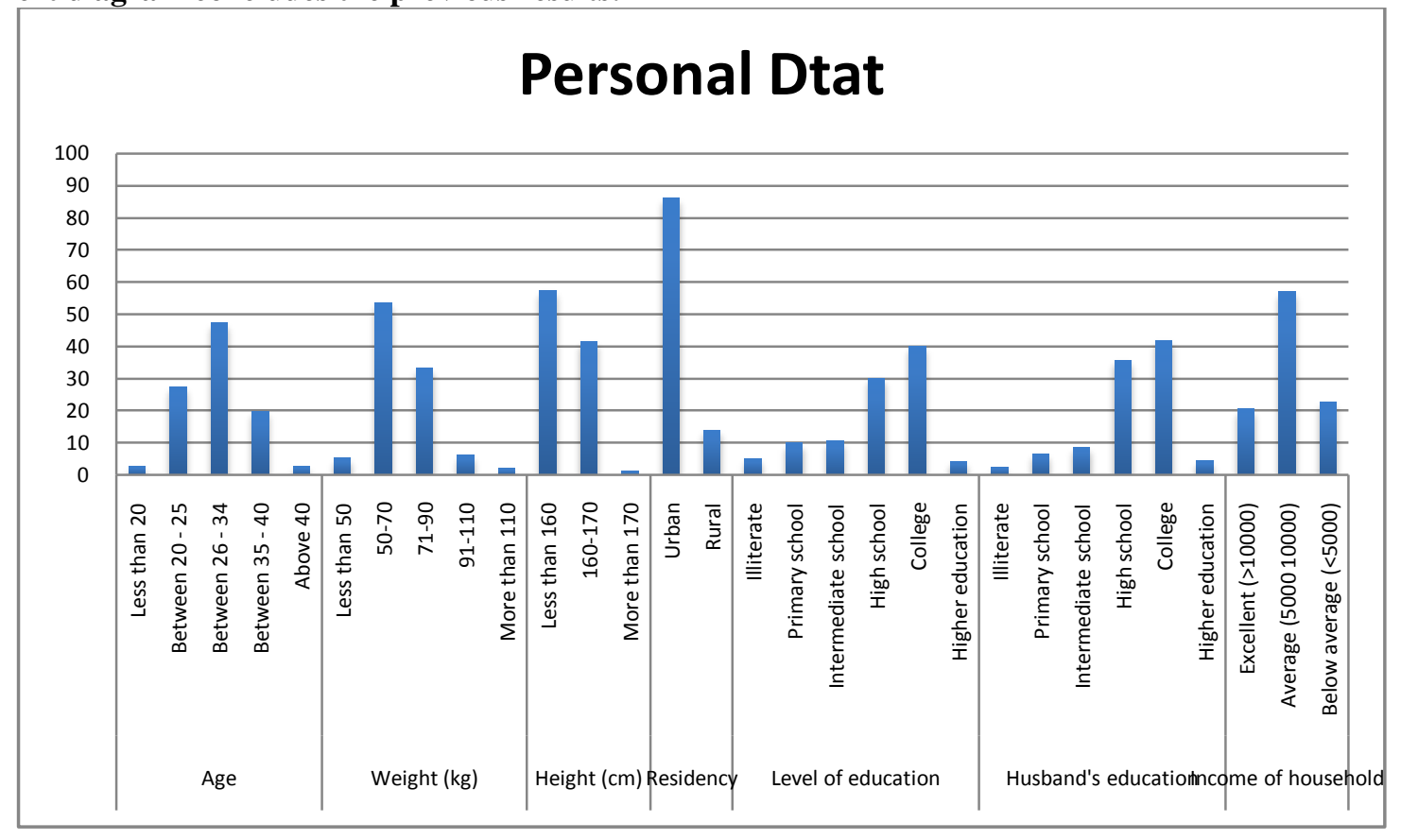

\section{Analysis of Results: -}

\section{First: Obstetric History:-}

The following table shows the participants' distribution according to their Gestational age; $36.2 \%$ of them were in the third trimester, while $8.7 \%$ of them were in the first trimester, $7.7 \%$ of them were in the second trimester, $43.4 \%$ of them had given birth to their babies, and only $4 \%$ of them weren't pregnant.

\begin{tabular}{|l|l|l|}
\hline Gestational age & Frequency & Percent \\
\hline First trimester (1-12) & 141 & 8.7 \\
\hline Second trimester (13-26) & 124 & 7.7 \\
\hline Third trimester (27-end of pregnancy) & 585 & 36.2 \\
\hline Delivered & 702 & 43.4 \\
\hline Not pregnant & 65 & 4.0 \\
\hline Total & 1617 & 100.0 \\
\hline
\end{tabular}

The next table shows the participants' distribution according to the number of pregnancies; number of deliveries, and number of miscarriages; $47.8 \%$ of them have already been pregnant for (2-4) times, while $22.9 \%$ of them got already pregnant just once, $15.6 \%$ of them have already been pregnant for (5- 6) times, and $13.7 \%$ of them have already been pregnant for more than (6) times. And according to the number of deliveries; $32.9 \%$ of them delivered from 2 to 3 babies, while $23.3 \%$ of them delivered just one baby, and $16.6 \%$ of then have never delivered any baby.The participants' distribution according to the number of miscarriages; $67.4 \%$ have never miscarriage their babies, while $28.1 \%$ of them had (1-2) miscarriages, $4.1 \%$ of them had (4- 5) miscarriages, and $0.4 \%$ of them had more than (5) miscarriages.

\begin{tabular}{|l|l|l|l|l|}
\hline Variable & H & H & P-value \\
\hline \multirow{5}{*}{ Gravidity } & 1 & 370 & 22.9 & \multirow{2}{*}{$0.00^{* *}$} \\
\cline { 2 - 4 } & $2-4$ & 773 & 47.8 & \\
\cline { 2 - 4 } & $5-6$ & 252 & 15.6 & \\
\cline { 2 - 4 } & More than 6 & 222 & 13.7 & \\
\hline \multirow{5}{*}{ Parity } & Nulliparous & 269 & 16.6 & \multirow{3}{*}{$0.00^{* *}$} \\
\cline { 2 - 4 } & Primiparous & 377 & 23.3 & \\
\cline { 2 - 4 } & $2-3$ & 532 & 32.9 & \\
\cline { 2 - 4 } & $4-5$ & 265 & 16.4 & \\
\hline
\end{tabular}




\begin{tabular}{|l|l|l|l|l|}
\hline \multirow{4}{*}{ Abortion } & More than 5 & 174 & 10.8 & \\
\cline { 2 - 4 } & None & 1090 & 67.4 & \\
\cline { 2 - 4 } & $1-2$ & 454 & 28.1 \\
\cline { 2 - 4 } & $3-5$ & 67 & 4.1 \\
\cline { 2 - 4 } & More than 5 & 6 & 0.4 & \\
\hline
\end{tabular}

Chi-squared test: *Significant at $0.05 \quad * *$ Significant at 0.01

The next table shows the women participants' distribution according to whether they ever had abnormal pregnancies as ectopic or cluster pregnancy; according to the ectopic pregnancy; $97.1 \%$ of them have never had this type of abnormal pregnancy, while $2.7 \%$ of them have had ectopic pregnancy once or twice, $0.2 \%$ of them had it from (3-5) times. And according to the cluster pregnancy; $99.4 \%$ of them have never had this type of abnormal pregnancy, while $0.4 \% \%$ of them have had ectopic pregnancy once or twice, $0.2 \%$ of them had it from (3-5) times.

\begin{tabular}{|l|l|l|l|l|}
\hline Ectopic & $1570(97.1)$ & $43(2.7)$ & $4(.2)$ & $0.00^{* *}$ \\
\hline Molar & $1607(99.4)$ & $7(.4)$ & $3(.2)$ & $0.00^{* *}$ \\
\hline
\end{tabular}

Chi-squared test: *Significant at $0.05 \quad * *$ Significant at 0.01

The following table shows the distribution of participants in terms of the number of times each birth is natural, assisted or cesarean. For natural childbirth $37.8 \%$ of the participants never had a natural birth while $17.2 \%$ had it once before and $23.7 \%$ had two or three natural births and a $21.2 \%$ had more than 3 . The participants' distribution according to Assisted delivery it's found that $96 \%$ of the participants never used this method before while $2.7 \%$ used it once before and a $0.9 \%$ tried it two or three times and only $0.4 \%$ used it more than three times. The distribution regarding cesarean delivery, $65.5 \%$ from the participants never had a cesarean delivery while $20.3 \%$ tried it once, $11.8 \%$ tried it two or three times and $2.5 \%$ tried it more than three times.

\begin{tabular}{|l|l|l|l|l|l|}
\hline Normal spontaneous delivery & $612(37.8)$ & $278(17.2)$ & $384(23.7)$ & $343(21.2)$ & $0.00^{* *}$ \\
\hline Assisted delivery & $1552(96.0)$ & $44(2.7)$ & $15(.9)$ & $6(.4)$ & $0.00^{* *}$ \\
\hline Cesarean Section & $1059(65.5)$ & $328(20.3)$ & $190(11.8)$ & $40(2.5)$ & $0.00^{* *}$ \\
\hline
\end{tabular}

Chi-squared test: *Significant at $0.05 * *$ Significant at 0.01

The following diagram illustrates the reasons for caesarean section for those who gave birth this way, where it's found that $27 \%$ of those who have it suffered from abnormal fetal position, and $25 \%$ the reason was fetal distress, and $10 \%$ due to CPD, and $4 \%$ due Antepartum hemorrhage, and 4\% also due to Preeclampsia, and 3\% due to carrying twins, and $27 \%$ for other reasons.

\section{Cesarian Section causes}

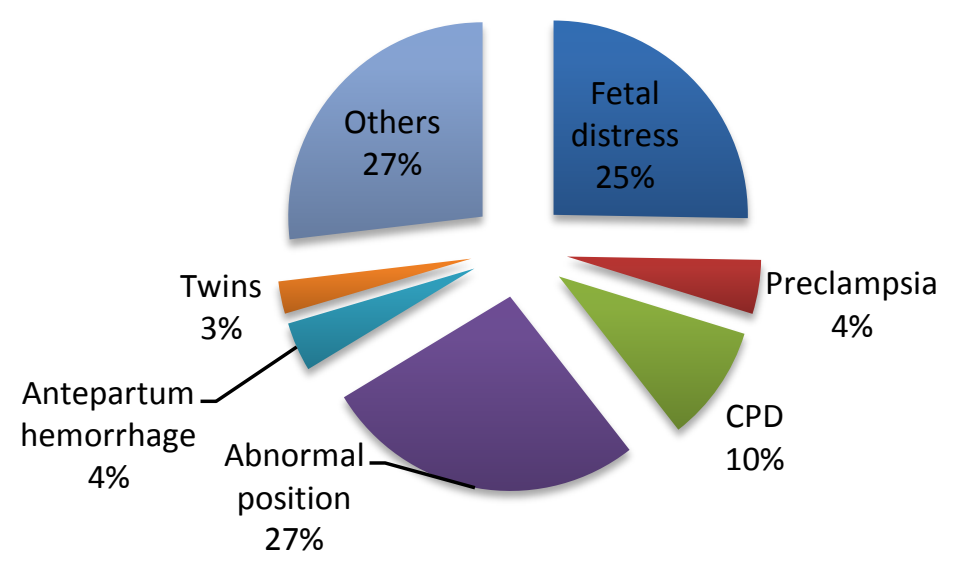

Second: Maternal health 
The following diagram shows the distribution of the sample in terms of smoking; where we note that $99 \%$ of women were non-smokers, while only $1 \%$ smokers.

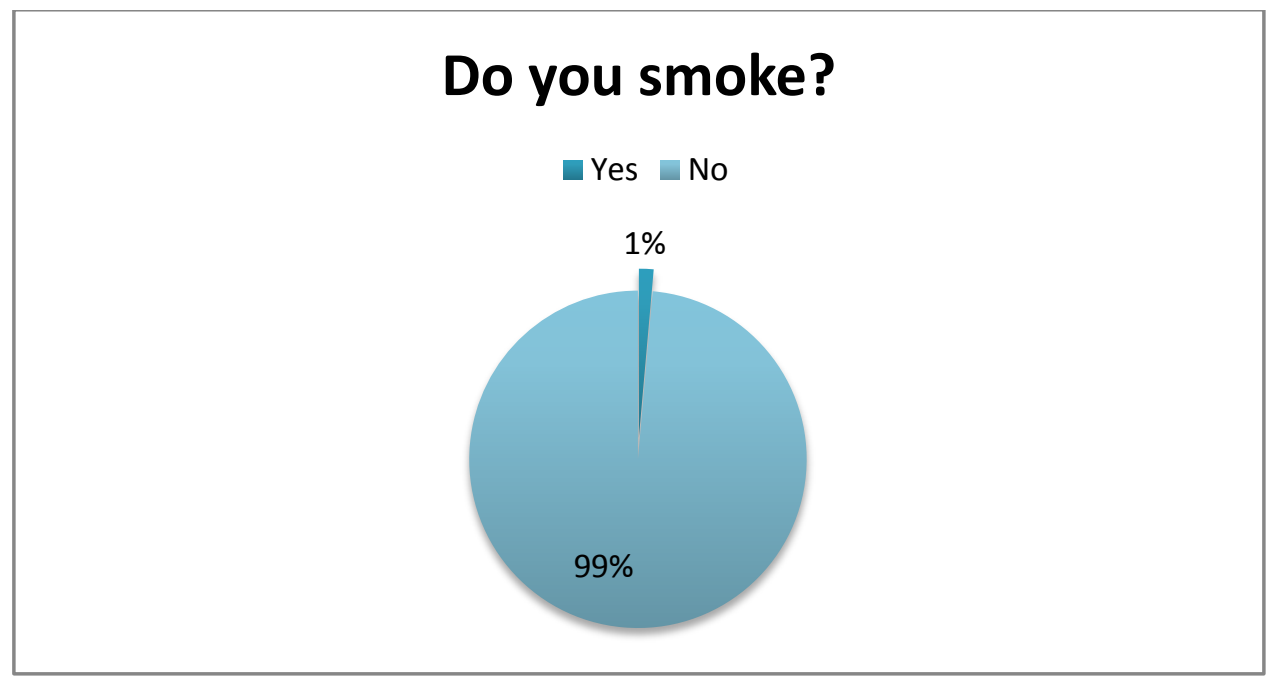

The following table shows a group of diseases of the participants.

\begin{tabular}{|l|l|l|l|}
\hline Diabetes & $108(6.7)$ & $1509(93.3)$ & $0.00^{* *}$ \\
\hline Asthma & $63(3.9)$ & $1554(96.1)$ & $0.00^{* *}$ \\
\hline Hypertension & $50(3.1)$ & $1567(96.9)$ & $0.00^{* *}$ \\
\hline Epilepsy & $3(.2)$ & $1614(99.8)$ & $0.00^{* *}$ \\
\hline Sickle cell anemia & $5(.3)$ & $1612(99.7)$ & $0.00^{* *}$ \\
\hline Iron deficiency anemia & $399(24.7)$ & $1218(75.3)$ & $0.00^{* *}$ \\
\hline Urinary tract infection & $441(27.3)$ & $1176(72.7)$ & $0.00^{* *}$ \\
\hline Cardiac diseases & $16(1.0)$ & $1601(99.0)$ & $0.00^{* *}$ \\
\hline Systemic Lupus Erythematosus (SLE) & $6(.4)$ & $1611(99.6)$ & $0.00^{* *}$ \\
\hline Scleroderma (Systemic Sclerosis) & $2(.1)$ & $1615(99.9)$ & $0.00^{* *}$ \\
\hline
\end{tabular}

Chi-squared test: *Significant at $0.05 * *$ Significant at 0.01

It is noted from the above table that $6.7 \%$ of participants have diabetes, while $93.3 \%$ doesn't have diabetes , and $3.9 \%$ asthmatics, while the $96.1 \%$ non-asthmatics, $3.1 \%$ for patients with high blood pressure, while $96.9 \%$ were free of blood pressure, and $0.2 \%$ patients with epilepsy, while $99.8 \%$ is living without epilepsy, and $0.3 \%$ sickle-cell anemia, while $99.7 \%$ are not affected, and $24.7 \%$ of participants has iron deficiency anemia, while $75.3 \%$ of them are not diseased with it, and $27.3 \%$ people has rheumatoid urinary tract, while $72.7 \%$ is not diseased with it, and $1 \%$ of the participants diagnosed with heart disease, while $99 \%$ were free of heart disease, and $0.4 \%$ of the participants diagnosed with Systemic Lupus Erythematosus (SLE), while 99.6\% are not affected, and finally, $0.1 \%$ of them are living with scleroderma, while $99.9 \%$ are not diseased by it.

\section{Third: Booking:-}

The following table shows the distribution of participants according to the month that the pregnant woman started her pregnancy follow-up with the doctor, It's noted that $80.9 \%$ of participants started their follow-up at the first or second month of pregnancy, while $13.9 \%$ they began to pursue their pregnancy follow up with the doctor in the third month to the fifth of pregnancy, and $1.1 \%$ started at the sixth or seventh month and $0.4 \%$ of them began to get there to follow up in the eighth or ninth month.

\begin{tabular}{|l|l|l|}
\hline $1-2$ months & 1309 & 80.9 \\
\hline $3-5$ months & 225 & 13.9 \\
\hline $6-7$ months & 18 & 1.1 \\
\hline $8-9$ months & 7 & .4 \\
\hline I have not had a booking appointment & 58 & 3.6 \\
\hline Total & 1617 & 100.0 \\
\hline
\end{tabular}


The following table shows the place of the follow-up of pregnant women; where we find that $45.9 \%$ of women go to private hospitals, while $23.6 \%$ of them to primary care centers and $16.1 \%$ of them do their follow-up in women and children's hospital, and 10.8 in other government hospitals.

\begin{tabular}{|l|l|l|}
\hline MCH & 260 & 16.1 \\
\hline Private hospitals & 742 & 45.9 \\
\hline Other government hospitals & 175 & 10.8 \\
\hline Primary health care & 382 & 23.6 \\
\hline I don't follow up & 58 & 3.6 \\
\hline Total & 1617 & 100.0 \\
\hline
\end{tabular}

The following diagram shows the ladies knowledgeof the importance of the first visit and the importance of continued follow-up in the same place, It's noted in the figure that $51 \%$ of women have a good awareness of this, while $17 \%$ do not have as much awareness as needed, and $32 \%$ have no awareness at all.

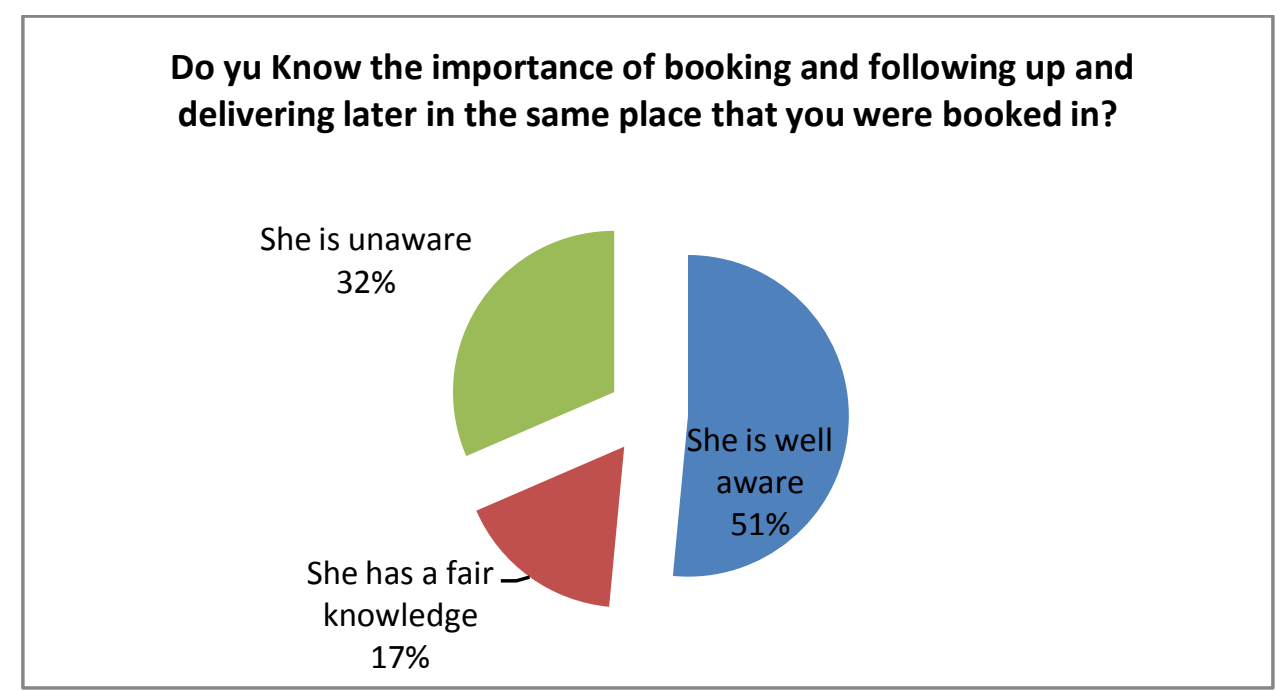

From the diagram, it concludes that $72.5 \%$ of women follow-up their pregnancy at the same place they visited at the first time, while $23 \%$ continued their follow-up elsewhere.

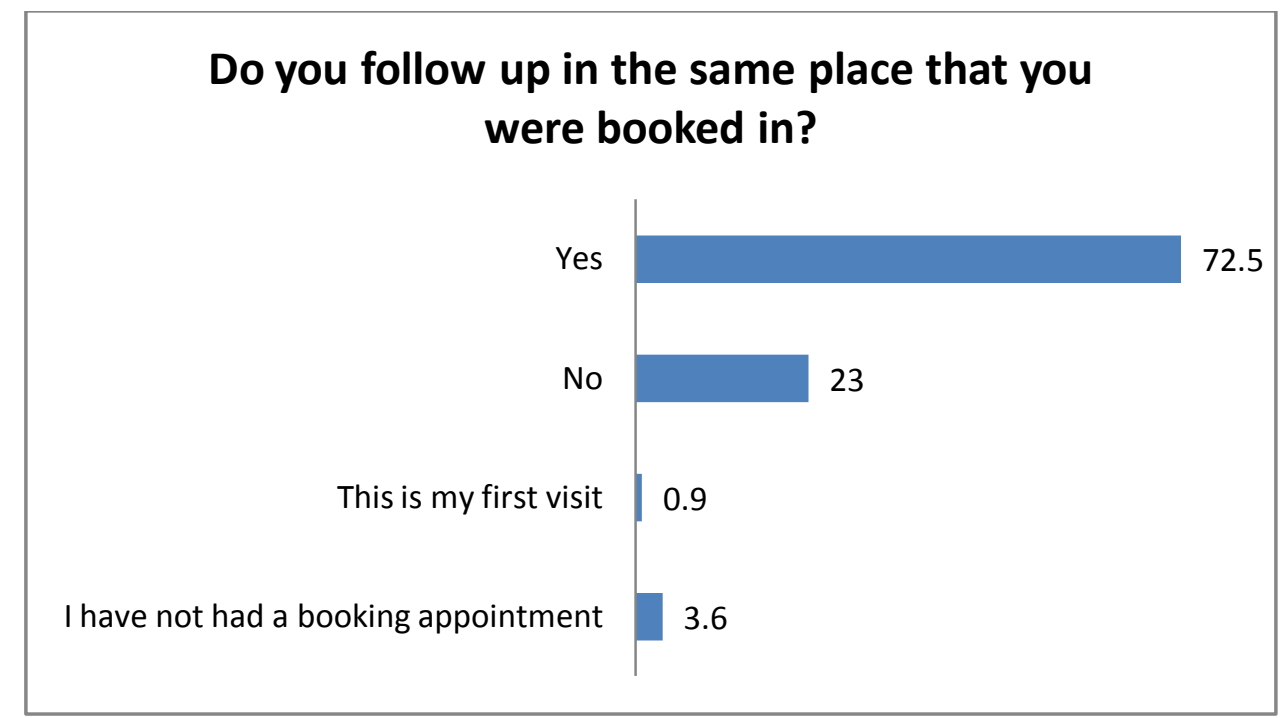

And when asked about the reason that some of the woman changed the first place of their pregnancy follow-ups they answered as follow, $37 \%$ of them changed the place because of the quality of services provided, and $16 \%$ changed it because of lack of transportation, and $7 \%$ for financial reasons and $7 \%$ due to negligence, and $5 \%$ because of the 
long wait times and congestion, and $5 \%$ due to the attitude of the physician, and $35 \%$ change the place up for other reasons.

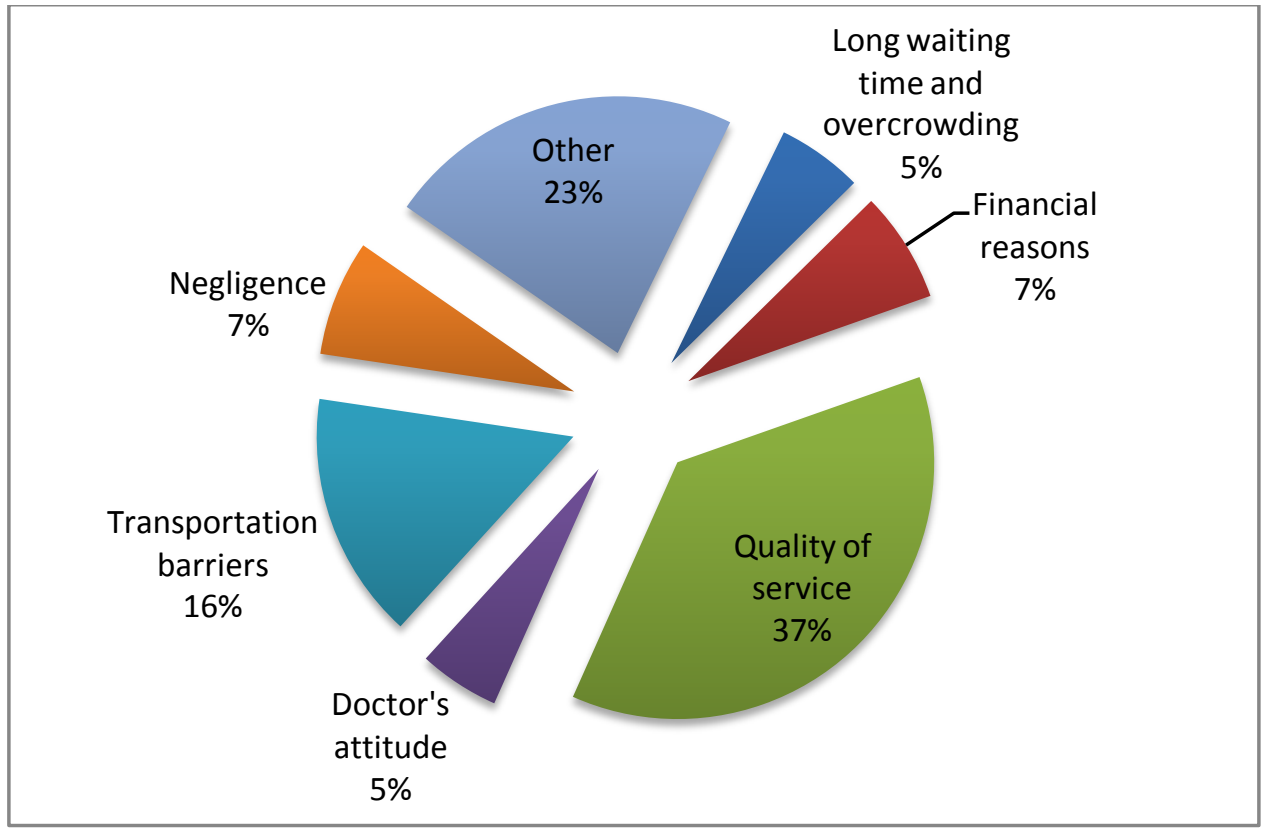

Fourth: ANC related questions: -

The following table shows the distribution of participants in terms of whether they are following up their pregnancies consistently and regularly, and it's noted that $80.1 \%$ are getting them consistently and regularly, while $16.4 \%$ are not.

\begin{tabular}{|l|l|l|}
\hline Yes & 1294 & 80.1 \\
\hline No & 265 & 16.4 \\
\hline I don't follow up at all & 58 & 3.6 \\
\hline Total & 1617 & 100.0 \\
\hline
\end{tabular}

Women who don't follow their pregnancy consistently and regularly were asked about the reason and $45 \%$ of them said it was neglect, while $22 \%$ was the lack of transportation, and $4 \%$ because of the long wait times, and $3 \%$ due to the quality of services, and $22 \%$ for other reasons.

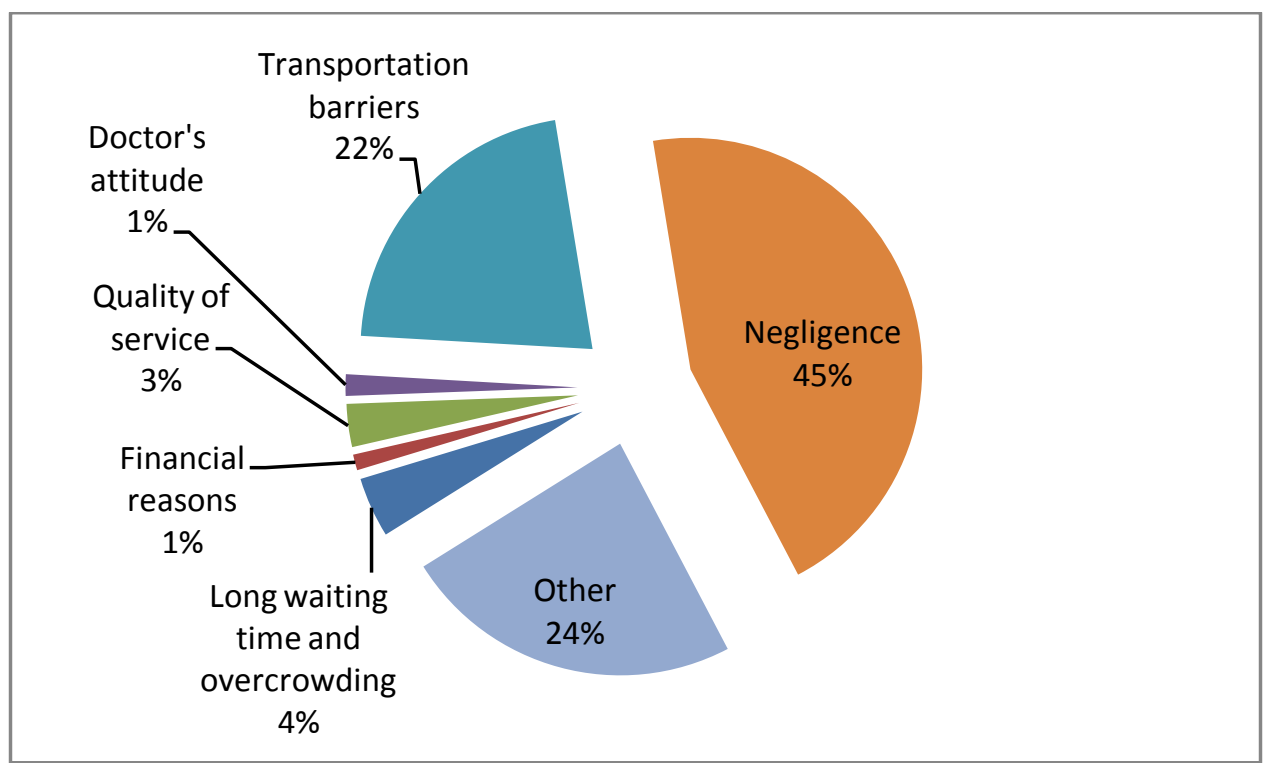


The following table shows the distribution of the sample in terms of how they believe the importance of the followup of pregnancy during the whole pregnancy; it's noted that that $89.7 \%$ believe in the importance of the follow-up, while $10.3 \%$ do not.

\begin{tabular}{|l|l|l|}
\hline Yes & 1450 & 89.7 \\
\hline No & 167 & 10.3 \\
\hline Total & 1617 & 100.0 \\
\hline
\end{tabular}

The following figure shows the distribution of participants according to whether daily work duties affect their presence to the pregnancy follow-ups, and answered $85.8 \%$ said that work duties do not have an impact on the visits, while $11.2 \%$ of women answered that daily duties and work have an impact on their attendance to pregnancy followup.

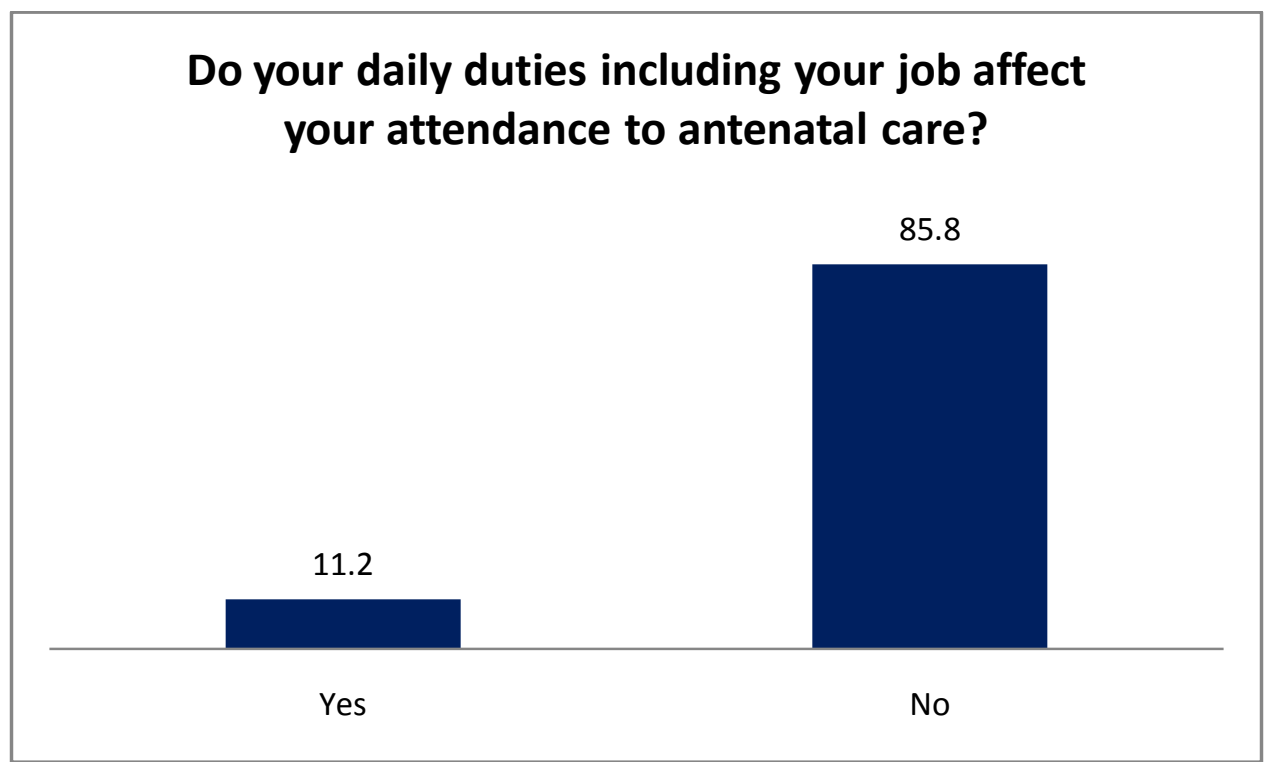

The following figure shows the distribution of participants by whether the busyness of their husbands affect one way or another their attendance to prenatal care, and answered $75.4 \%$ of women are not affected by it, while $21.7 \%$ of women is affected by it.

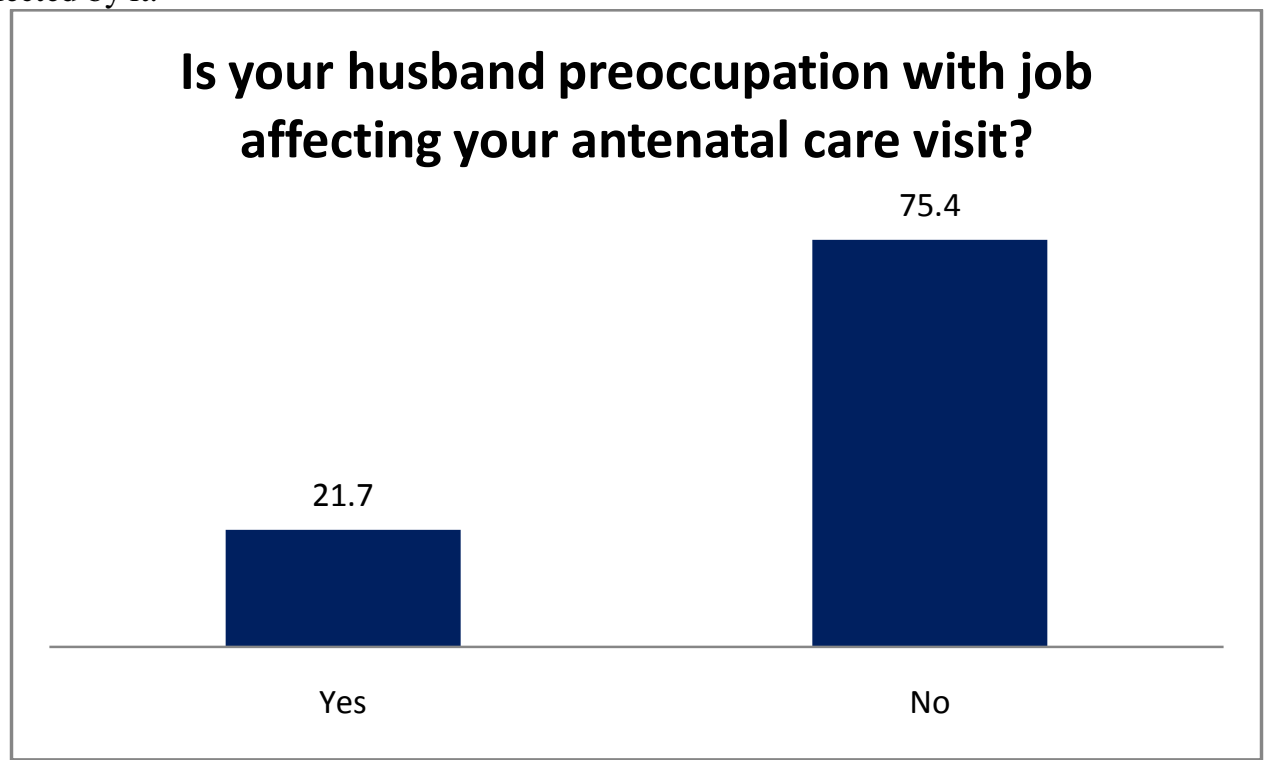


Fifth: Supplements: -

The following table shows some of the supplements that pregnant women uses during pregnancy, and the proportions of each of them. For folic acid, we note that $92.1 \%$ of women take it during pregnancy, and for vitamin $\mathrm{D}$, we find that $38.5 \%$ of women take it, while for iron, we find that $82 \%$ of women have it during pregnancy, and for calcium, we find that $75.6 \%$ of women have it during pregnancy.

\begin{tabular}{|l|l|l|l|}
\hline Folic acid & $1490(92.1)$ & $127(7.9)$ & $0.00^{* *}$ \\
\hline Vitamin D & $622(38.5)$ & $995(61.5)$ & $0.00^{* *}$ \\
\hline Iron supplements & $1326(82.0)$ & $291(18.0)$ & $0.00^{* *}$ \\
\hline Calcium & $1223(75.6)$ & $394(24.4)$ & $0.00^{* *}$ \\
\hline
\end{tabular}

Chi-squared test: $*$ Significant at $0.05 * *$ Significant at 0.01

The following diagram shows the distribution of the sample in terms of the extent of their belief that the use of complementary grain during pregnancy reduces the incidence of some of the problems related to pregnancy, where we note that $89 \%$ of the participants believe so, and only11\% of them do not believe so.

\section{Do you think taking vital supplements during pregnancy can reduce pregnancy related problems?}

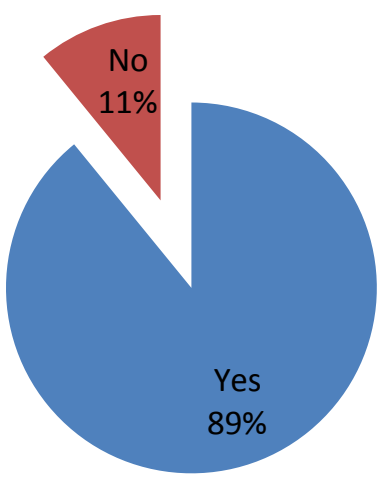

\section{Sixth: Satisfaction: -}

The following table shows some of the things that women may not be satisfied with during the follow-up of pregnancy, $86.4 \%$ of women are not happy about the number of visits, and for the time between visits found that $83.4 \%$ of women are unhappy with it, but for the time being spend with your physician there were $89.1 \%$ of women are not satisfied, and for the waiting times it was found that $67.4 \%$ of women are not satisfied.

\begin{tabular}{|l|l|l|l|}
\hline Number of visits & $1397(86.4)$ & $220(13.6)$ & $0.00^{* *}$ \\
\hline Spacing between visits & $1348(83.4)$ & $269(16.6)$ & $0.00^{* *}$ \\
\hline Time spent with provider & $1441(89.1)$ & $176(10.9)$ & $0.00^{* *}$ \\
\hline Waiting time & $1090(67.4)$ & $527(32.6)$ & $0.00^{* *}$ \\
\hline
\end{tabular}

Chi-squared test: *Significant at $0.05 * *$ Significant at 0.01

\section{Seventh: Outcome: -}

The following chart explains a variety of pregnancy related subjects,For the type of birth, found that $66.6 \%$ of women have natural childbirth, while $33.4 \%$ had Caesarean birth.As for the gender, there were $52.2 \%$ of male births, while $47.8 \%$ of female births. The percentage of babies born weighing less than $2.5 \mathrm{~kg}$ is $13.2 \%$, while the percentage of babies born weighing $(2.5-3 \mathrm{~kg})$ is $52.9 \%$, and those born weighing somewhere between $(3.1-4 \mathrm{~kg})$ is $32.5 \%$, and percentage of babies born weighing more than $4 \mathrm{~kg}$ were is $1.4 \%$.It found that 28.9 percent of births were transferred to the intensive care unit for newborns, while $71.1 \%$ of births have not been transferred to the unit care center for newborns. 


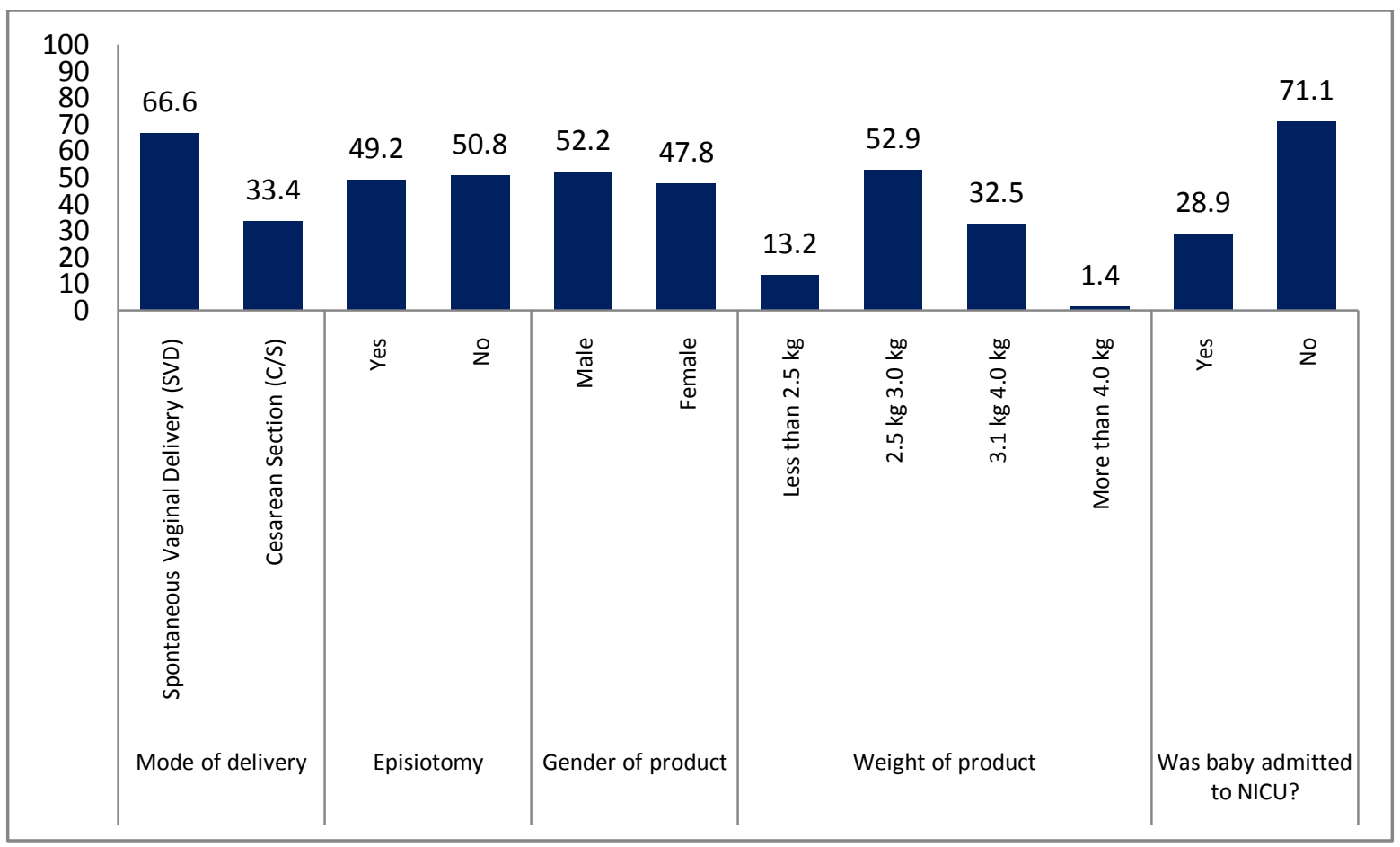

Eighth: Relationships and correlations: -

The first hypothesis states that there is a relation between get booking appointment and each of (Age, Residency, Level of education, Income of household, and Gravidity).

Using the Chi-Square test was tested the NULL hypothesis which states that there is no relation between get booking appointment and each of (Age, Residency, Level of education, Income of household, and Gravidity), versus the alternative hypothesis which states that there is a relation between get booking appointment and each of (Age, Residency, Level of education, Income of household, and Gravidity), the next table shows the test results.

\begin{tabular}{|c|c|c|c|c|c|c|c|c|}
\hline & \multicolumn{5}{|l|}{ When } & \multirow[t]{2}{*}{ Chi- } & \multirow[t]{2}{*}{$P-v a$} \\
\hline & & $\begin{array}{l}1-2 \\
\text { months }\end{array}$ & $\begin{array}{l}3-5 \\
\text { months }\end{array}$ & $\begin{array}{l}6-7 \\
\text { months }\end{array}$ & $\begin{array}{lr}8-9 \\
\text { months }\end{array}$ & $\begin{array}{l}\text { I have not } \\
\text { had a } \\
\text { booking } \\
\text { appointment }\end{array}$ & & \\
\hline \multirow{5}{*}{$\underset{8}{4}$} & Less than 20 & 37 & 6 & 0 & 0 & 1 & \multirow[t]{5}{*}{45.039} & \multirow[t]{5}{*}{$.000^{*}$} \\
\hline & 2025 & 384 & 47 & 4 & 0 & 10 & & \\
\hline & 2634 & 626 & 103 & 9 & 5 & 21 & & \\
\hline & 3540 & 240 & 60 & 5 & 2 & 13 & & \\
\hline & Above 40 & 28 & 9 & 0 & 0 & 7 & & \\
\hline \multirow{2}{*}{ 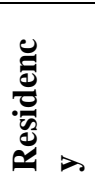 } & Urban & 1149 & 183 & 16 & 4 & 39 & \multirow[t]{2}{*}{16.353} & \multirow[t]{2}{*}{$.003 *$} \\
\hline & Rural & 166 & 42 & 2 & 3 & 13 & & \\
\hline \multirow{6}{*}{ 氖 } & Illiterate & 60 & 13 & 1 & 1 & 8 & \multirow[t]{6}{*}{65.786} & \multirow[t]{6}{*}{$.000 *$} \\
\hline & Primary school & 113 & 29 & 6 & 2 & 10 & & \\
\hline & Intermediate school & 129 & 29 & 3 & 2 & 8 & & \\
\hline & High school & 386 & 83 & 4 & 1 & 12 & & \\
\hline & College & 568 & 63 & 4 & 1 & 11 & & \\
\hline & Higher education & 59 & 8 & 0 & 0 & 3 & & \\
\hline$-=$ & Excellent $(>10000)$ & 273 & 47 & 3 & 1 & 7 & 11.977 & .152 \\
\hline
\end{tabular}




\begin{tabular}{|c|c|c|c|c|c|c|c|c|}
\hline & $\begin{array}{ll}\text { Average } & (5000 \\
10000) & \end{array}$ & 761 & 122 & 7 & 4 & 27 & & \\
\hline & $\begin{array}{ll}\text { Below } & \text { average } \\
(<5000) & \end{array}$ & 281 & 56 & 8 & 2 & 18 & & \\
\hline & 1 & 334 & 28 & 1 & 0 & 7 & 72.166 & $.000^{*}$ \\
\hline$\equiv$ & $2-4$ & 636 & 110 & 9 & 2 & 16 & & \\
\hline 完 & $5-6$ & 199 & 38 & 3 & 3 & 9 & & \\
\hline$\tilde{E}$ & More than 6 & 146 & 49 & 5 & 2 & 20 & & \\
\hline
\end{tabular}

*Significant at the 0.05 level

We conclude from the above table that: -

1. There is a relation between get booking appointment and Age, where the P-value was less than 0.05 level.

2. There is a relation between get booking appointment andResidency, where the P-value was less than 0.05 level.

3. There is a relation between get booking appointment and Level of education where the P-value was less than 0.05 level.

4. There is a relation between get booking appointment and Gravidity where the P-value was less than 0.05 level.

5. There is no relation between get booking appointment and Income of household where the P-value was more than 0.05 level.

The second hypothesis states that there is a relation between the knowledge of the importance of booking and following up and delivering later in the same place, and each of (Age, Residency, Level of education, Income of household, and Gravidity).

Using the Chi-Square test was tested the NULL hypothesis which states that there is no relation between the knowledge of the importance of booking and following up and delivering later in the same place, and each of (Age, Residency, Level of education, Income of household, and Gravidity), versus the alternative hypothesis which states that there is a relation between the knowledge of the importance of booking and following up and delivering later in the same place, and each of (Age, Residency, Level of education, Income of household, and Gravidity), the next table shows the test results.

\begin{tabular}{|c|c|c|c|c|c|c|}
\hline & & $\begin{array}{l}\text { She is } \\
\text { well } \\
\text { aware }\end{array}$ & $\begin{array}{l}\text { She has a } \\
\text { fair } \\
\text { knowledge }\end{array}$ & $\begin{array}{l}\text { She is } \\
\text { unaware }\end{array}$ & & \\
\hline \multirow{5}{*}{ Age } & Less than 20 & 11 & 10 & 23 & \multirow[t]{5}{*}{16.062} & \multirow[t]{5}{*}{$.042 *$} \\
\hline & 2025 & 224 & 71 & 150 & & \\
\hline & 2634 & 400 & 132 & 232 & & \\
\hline & 3540 & 174 & 55 & 91 & & \\
\hline & Above 40 & 24 & 7 & 13 & & \\
\hline \multirow{2}{*}{ Residency } & Urban & 738 & 240 & 413 & \multirow{2}{*}{15.038} & \multirow{2}{*}{$.001^{*}$} \\
\hline & Rural & 95 & 35 & 96 & & \\
\hline \multirow{6}{*}{$\begin{array}{l}\text { Level } \\
\text { education }\end{array}$} & Illiterate & 32 & 19 & 32 & \multirow[t]{6}{*}{42.807} & \multirow[t]{6}{*}{$.000^{*}$} \\
\hline & Primary school & 63 & 29 & 68 & & \\
\hline & Intermediate school & 73 & 28 & 70 & & \\
\hline & High school & 245 & 91 & 150 & & \\
\hline & College & 373 & 97 & 177 & & \\
\hline & Higher education & 47 & 11 & 12 & & \\
\hline \multirow{3}{*}{$\begin{array}{l}\text { Income of } \\
\text { household }\end{array}$} & Excellent $(>10000)$ & 200 & 44 & 87 & \multirow[t]{3}{*}{15.472} & \multirow[t]{3}{*}{$.004 *$} \\
\hline & $\begin{array}{l}\text { Average } \\
10000)\end{array}$ & 464 & 165 & 292 & & \\
\hline & $\begin{array}{ll}\begin{array}{l}\text { Below } \\
(<5000)\end{array} & \text { average } \\
\end{array}$ & 169 & 66 & 130 & & \\
\hline \multirow[t]{4}{*}{ Gravidity } & 1 & 196 & 66 & 108 & \multirow[t]{4}{*}{3.052} & \multirow[t]{4}{*}{.802} \\
\hline & $2-4$ & 391 & 135 & 247 & & \\
\hline & $5-6$ & 133 & 35 & 84 & & \\
\hline & More than 6 & 113 & 39 & 70 & & \\
\hline
\end{tabular}

*Significant at the 0.05 level 
We conclude from the above table that:-

1. There is a relation between the knowledge of the importance of booking and following up and delivering later in the same place, and Age, where the P-value was less than 0.05 level.

2. There is a relation between the knowledge of the importance of booking and following up and delivering later in the same place, and Residency, where the P-value was less than 0.05 level.

3. There is a relation between the knowledge of the importance of booking and following up and delivering later in the same place, and Level of education, where the P-value was less than 0.05 level.

4. There is a relation between the knowledge of the importance of booking and following up and delivering later in the same place, and Income of household, where the P-value was less than 0.05 level.

5. There is no relation between the knowledge of the importance of booking and following up and delivering later in the same place, and Gravidity, where the P-value was more than 0.05 level.

The third hypothesis states that there is a relation between the regularly attendance to ANC, and each of (Age, Residency, Level of education, Income of household, and Gravidity).

Using the Chi-Square test was tested the NULL hypothesis which states that there is no relation between the regularly attendance to ANC, and each of (Age, Residency, Level of education, Income of household, and Gravidity), versus the alternative hypothesis which states that there is a relation between the regularly attendance to ANC, and each of (Age, Residency, Level of education, Income of household, and Gravidity), the next table shows the test results.

\begin{tabular}{|c|c|c|c|c|c|c|}
\hline & & Yes & No & $\begin{array}{l}\text { I don't } \\
\text { followup }\end{array}$ & & \\
\hline \multirow{5}{*}{ Age } & Less than 20 & 34 & 6 & 4 & \multirow[t]{5}{*}{10.694} & \multirow[t]{5}{*}{0.220} \\
\hline & 2025 & 350 & 71 & 24 & & \\
\hline & 2634 & 607 & 128 & 29 & & \\
\hline & 3540 & 258 & 52 & 10 & & \\
\hline & Above 40 & 31 & 8 & 5 & & \\
\hline \multirow{2}{*}{ Residency } & Urban & 1106 & 225 & 60 & \multirow[t]{2}{*}{.865} & \multirow[t]{2}{*}{0.649} \\
\hline & Rural & 174 & 40 & 12 & & \\
\hline \multirow{6}{*}{$\begin{array}{c}\text { Level of } \\
\text { education }\end{array}$} & Illiterate & 64 & 17 & 2 & \multirow[t]{6}{*}{5.117} & \multirow[t]{6}{*}{0.883} \\
\hline & Primary school & 121 & 32 & 7 & & \\
\hline & Intermediate school & 136 & 25 & 10 & & \\
\hline & High school & 390 & 77 & 19 & & \\
\hline & College & 514 & 102 & 31 & & \\
\hline & Higher education & 55 & 12 & 3 & & \\
\hline \multirow{3}{*}{$\begin{array}{l}\text { Income of } \\
\text { household }\end{array}$} & Excellent $(>10000)$ & 263 & 51 & 17 & \multirow[t]{3}{*}{2.754} & \multirow[t]{3}{*}{0.600} \\
\hline & Average (5000 10000) & 731 & 147 & 43 & & \\
\hline & $\begin{array}{c}\text { Below average } \\
(<5000)\end{array}$ & 286 & 67 & 12 & & \\
\hline \multirow[t]{4}{*}{ Gravidity } & 1 & 287 & 63 & 20 & \multirow[t]{4}{*}{7.369} & \multirow[t]{4}{*}{0.288} \\
\hline & $2-4$ & 621 & 120 & 32 & & \\
\hline & $5-6$ & 208 & 36 & 8 & & \\
\hline & More than 6 & 164 & 46 & 12 & & \\
\hline
\end{tabular}

*Significant at the 0.05 level

We conclude from the above table that:-

1. There is no relation between the regularly attendance to ANC, and Age, where the P-value was more than 0.05 level.

2. There is no relation between the regularly attendance to ANC, and Residency, where the P-value was more than 0.05 level.

3. There is no relation between the regularly attendance to ANC, and Level of education, where the P-value was more than 0.05 level.

4. There is no relation between the regularly attendance to ANC, and Income of household, where the P-value was more than 0.05 level. 
5. There is no relation between the regularly attendance to ANC, and Gravidity, where the P-value was more than 0.05 level.

The fourth hypothesis states that there is a relation between follow-up the regular antenatal care visits throughout the whole period of pregnancy, and each of (Age, Residency, Level of education, Income of household, and Gravidity).

Using the Chi-Square test was tested the NULL hypothesis which states that there is no relation between follow-up the regular antenatal care visits throughout the whole period of pregnancy, and each of (Age, Residency, Level of education, Income of household, and Gravidity), versus the alternative hypothesis which states that there is a relation between follow-up the regular antenatal care visits throughout the whole period of pregnancy, and each of (Age, Residency, Level of education, Income of household, and Gravidity), the next table shows the test results.

\begin{tabular}{|c|c|c|c|c|c|}
\hline \multirow{2}{*}{ Age } & & Yes & No & & \\
\hline & Less than 20 & 40 & 4 & \multirow[t]{5}{*}{.756} & \multirow[t]{5}{*}{.944} \\
\hline & 2025 & 397 & 48 & & \\
\hline & 2634 & 689 & 75 & & \\
\hline & 3540 & 284 & 36 & & \\
\hline & Above 40 & 40 & 4 & & \\
\hline \multirow[t]{2}{*}{ Residency } & Urban & 1253 & 138 & \multirow[t]{2}{*}{1.779} & \multirow[t]{2}{*}{.182} \\
\hline & Rural & 197 & 29 & & \\
\hline \multirow{6}{*}{$\begin{array}{ll}\text { Level } & \text { of } \\
\text { education } & \end{array}$} & Illiterate & 68 & 15 & \multirow[t]{6}{*}{14.152} & \multirow[t]{6}{*}{$.015^{*}$} \\
\hline & Primary school & 137 & 23 & & \\
\hline & Intermediate school & 147 & 24 & & \\
\hline & High school & 445 & 41 & & \\
\hline & College & 589 & 58 & & \\
\hline & Higher education & 64 & 6 & & \\
\hline \multirow{3}{*}{$\begin{array}{l}\text { Income } \\
\text { household }\end{array}$} & Excellent (>10000) & 303 & 28 & \multirow[t]{3}{*}{3.340} & \multirow[t]{3}{*}{.188} \\
\hline & Average $(500010000)$ & 828 & 93 & & \\
\hline & $\begin{array}{ll}\begin{array}{l}\text { Below } \\
(<5000)\end{array} & \text { average } \\
\end{array}$ & 319 & 46 & & \\
\hline \multirow[t]{4}{*}{ Gravidity } & 1 & 342 & 28 & \multirow[t]{4}{*}{4.677} & \multirow[t]{4}{*}{.197} \\
\hline & $2-4$ & 687 & 86 & & \\
\hline & $5-6$ & 221 & 31 & & \\
\hline & More than 6 & 200 & 22 & & \\
\hline
\end{tabular}

*Significant at the 0.05 level

\section{We conclude from the above table that:}

1. There is no relation between follow-up the regular antenatal care visits throughout the whole period of pregnancy, and Age, where the P-value was more than 0.05 level.

2. There is no relation between follow-up the regular antenatal care visits throughout the whole period of pregnancy, and Residency, where the P-value was more than 0.05 level.

3. There is a relation between follow-up the regular antenatal care visits throughout the whole period of pregnancy, and Level of education, where the P-value was less than 0.05 level.

4. There is no relation between follow-up the regular antenatal care visits throughout the whole period of pregnancy, and Income of household, where the P-value was more than 0.05 level.

5. There is no relation between follow-up the regular antenatal care visits throughout the whole period of pregnancy, and Gravidity, where the P-value was more than 0.05 level.

\section{Discussion: -}

World health organization (WHO) estimated thatannually 529,000 women die globally as a result of pregnancy and childbirth. ${ }^{28}$ Antenatal care (ANC) is an effective tool to reduce both infant and maternal mortality rates. ${ }^{1} \mathrm{Al}$ Otaiby et al., 2013 reported that antenatal knowledge scores were below average in Saudi Arabia. ${ }^{13}$ This study aimed to assess the awareness of antenatal care importance among pregnant women in Madina, Saudi Arabia and its relationship with certain variables such as age, educational level, socioeconomic status, gravidity, parity and number prenatal care visits. This study includes 1617 women, their Demographics shows that the majority of them between 
26-34 years old. About half of them had collage education and higher, while 35.7\% had High school, this show the high education for many of them. Only $2.5 \%$ of them had Illiterate husband. This education has been a great role in the interest of mothers in ANC. Several other studies also found a strong positive impact of mothers' education on the utilization of health services, ${ }^{15,16}$ because knowledge and education can improve the awareness of people about their rights and health. ${ }^{23}$ The study results showed good obstetric history, most of women have never miscarriage their babies, while $0.4 \%$ of them had more than (5) miscarriages. $37.8 \%$ of the participants never had a natural birth, and $96 \%$ of the women never used assisted delivery before 34.5\% had Cesarean Section for one time at least, The most common reason for $27 \%$ of those who have it suffered from abnormal embryonic situation.Vast majority nonsmokers, but at study in Lebanon almost one quarter (23\%) of participants reported smoking during pregnancy. ${ }^{17}$

It may be the reason for differing proportion between the two countries is different customs, traditions and the nature of society.Results of the study have shown that vast majority of mothers had healthy pregnancy, $99.4 \%$ of women have never had abnormal pregnancy.Generally, most of women have no diseases; the most common diseases were Urinary tract infection $27.3 \%$, followed by Iron deficiency anemia $24.7 \%$.In recent study Prevalence of anemia $(\mathrm{Hb}<11 \mathrm{gm} / \mathrm{dl})$ on pregnant women in Pakistan was found to be $96 \%{ }^{18}$ Iron, folate and vitamin supplements are routinely given to women attending antenatal care facilities along with advice for appropriate dietary practices to reduce anemia. $89 \%$ of the women believe that the use of complementary grain during pregnancy reduces the incidence of some of the problems related to pregnancy. Most of women take supplements that pregnant women use during pregnancy, such as; Folic acid, Vitamin D, Iron supplements, Calcium. in study in Pakistan, 64\% of the women had never used any haematinics. ${ }^{18}$ This may be due to differences in economic level between Saudi Arabia and Pakistan, so many women in Pakistan haven't get hematinics All the mothers had registered antenatal, this same to Javali et al. study. ${ }^{19}$ And Roy et al. study. ${ }^{20}$ But Gupta et al. found that $89.6 \%$ of women had registered themselves. ${ }^{21}$ This may be due to the low level of education and economic level in many areas in India.80.9\% of women started their follow-up at the first or second month of pregnancy. Gupta et al. found that $74.4 \%$ started their follow-up at the first or second month of pregnancy. ${ }^{21}$ Javali et al., reported that $56.5 \%$ and $42.9 \%$ women under ANC registration in the 1 st trimester and the 2 nd trimester, respectively. ${ }^{19}$ Berhe et al., reported that $48 \%, 42.4 \%$ women made their first visit in the 1st trimester, 2nd trimester. ${ }^{22}$ More than half of women have a good awareness about knowledge of the importance of the first visit and the importance of continued follow-up in the same place. $72.5 \%$ of women follow-up their pregnancy at the same place they visited at the first time. $89.7 \%$ believe in the importance of the follow-up pregnancy during the whole pregnancy, while $80.1 \%$ are getting their pregnancies consistently and regularly, the most common reason for don't follow their pregnancy consistently and regularly was neglect.According to our results there was a relation between get booking appointment and age, residency, level of education, graviditywhere the P-value was less than 0.05 level. But there was no relation between get booking appointment and income of household where the P-value was more than 0.05 level.Also in our study,there is a relation between the knowledge of the importance of booking and following up and delivering later in the same place, and age, residency, level of education, income of household where the P-value was less than 0.05 level. But there was no relation between the knowledge of the importance of booking and following up and delivering later in the same place, and gravidity, where the P-value was more than 0.05 level.According to our results there was no relation between regularly attendance to ANC, or follow-up the regular antenatal care visits throughout the whole period of pregnancy, and age. This finding conforms a studyin India found that maternal age was not statistically associated with ANC.$^{24}$ But conflict with many other studies which found that maternal age is one of the important predictors for ANC, it was found that the young women were more likely to seek antenatal care than older one. ${ }^{25,26}$ The reason of difference in the results is the difference in economic and cultural levels between the target groups in the two studies. Also in our study, there was no relation between regularly attendance to ANC, or follow-up the regular antenatal care visits throughout the whole period of pregnancy, and income of household, where the P-value was more than 0.05 level. Because most of the services of ANC in KSA rely on health insurance and therefore does not pose a financial burden on the family.There was a relation between follow-up the regular antenatal care visits throughout the whole period of pregnancy, and level of education where the P-value was less than 0.05 level. This conform previous studies found a strong positive impact of mothers' education on the utilization of health services. $^{15,16}$ This is considered normal because whenever greater the parent level of education and culture, it increased awareness of their rights and the importance of the ANC. There was no relation between regularly attendance to ANC, or follow-up the regular antenatal care visits throughout the whole period of pregnancy, and graviditywhere the P-value was more than 0.05 level. While study in Nepalrevealed that there was statistically significant association between numbers of childbirth and the ANC visits $(\mathrm{p}<0.05) .{ }^{27}$ The results of our study differ from the results of the study in Nepal because the level of education in Nepal is less than it in Saudi Arabia, as well 
as economic level, so in Nepal mothers experience of pregnancy and delivery made them believe their maternal health knowledge was adequate.

\section{Limitations: -}

The generalizability of these results is subject to certain limitations. For instance, limited time allocated for study, since data has been collected in less than one month. The study was conducted only in 2 major hospitals, and inclusion of a greater number of centers or comparisons of urban and rural centers was not feasible. Lack of sufficient cooperation from the health institutions to provide information pertaining to patients. A worth mentioning limitation in this study is the unavailability of experts' opinion on the recommended content and delivery methods for antenatal education from the providers of this service. Knowing the providers' point of view and combining it with the responses of the target population will add to the validity of this study and will help in the development of effective antenatal education programs. More in-depth study of the sociodemographic aspects and job satisfaction of the health care providers would also be useful to give a more accurate measure of overall performance. Also, the rarity of study's topic in Saudi Arabia made us face many obstacles especially in the literature review. Furthermore, the scope of this study was limited in terms of its external validity. The methodology that was implemented in data collection yielded qualitative data that only can be interpreted relative to participants' populations.

\section{Conclusions: -}

In summary, all the mothers had registered antenatal Care, the education has been a great role in the interest of mothers in ANC. Most of women have no diseases, and they believe that the use of complementary grain during pregnancy reduces the incidence of some of the problems related to pregnancy. More than half of women have a good awareness about knowledge of the importance of the first visit and the importance of continued follow-up in the same place.There was no relation between the regularly attendance to ANC, and age, gravidity, residency, level of education, income of household. Also, there was no relation between follow-up the regular antenatal care visits throughout the whole period of pregnancy, and age, gravidity, residency, income of household. But there was a relation between follow-up the regular antenatal care visits throughout the whole period of pregnancy, and level of education

\section{Recommendations: -}

Based on the findings of the present study, the following recommendations are suggested:

1. Enhance strategies to increase awareness of importance of follow up and delivery later at the same place of booking

2. Government should increase number of health care centers and improve the quality of services provided at these centers. Also, should recruit large numbers of qualified health care providers to decrease work load on the staff and to give each patient her full time of examination and consultation.

3. The patient's medical files should be linked by system in all hospitals of the kingdom so when patient change her hospital the other hospitals and health care centers can easily reach to her information.

4. Patient satisfaction surveys should be carried out routinely to improve the quality of services.

5. Different health education methods should be available to increase awareness of the women about the importance and components of antenatal care and how that help in deceasing the complication of pregnancy.

6. enhance the rule of family physician to let the population trust them and follow up at health care centers.

7. Mass media including social media should play a consequential role in presenting the benefits of prenatal care like early diagnosis and treatment of some possible complications during pregnancy.

8. It would be more advantageous to attempt to re-conduct the study with a much larger sample size, and to carry out the study across many other cultural backgrounds and demographical aspects.

9. Further studies should be conducted to incorporate the views and responses of health care providers, as the study only depended on the responses of Saudi women.

10. Further research is recommended on the evaluation of the content of antenatal education and its cultural relevance. 


\section{Acknowledgement: -}

At the outset, we would like to express our deep and sincere gratitude to the following people without whose support this research project would not have been a success. We would like to sincerely thank all the data collectors who helped us in our project, namely: Rawan Ghazi Shukri, Alhassan Ali Alghamdi, Abdullah Hasan Alhojaili, Daniyah Saud Aloufi, Somaya Soliman Alsuhaimi, Fatin Salem Almaa'shi, Areej Mustafa Alawfi, Bashaer Abdulbaqi Ben Yayh, Raghad Zaid Aljuhani, Razzan Mohammed Ghazi, Abdulrahman Thaher Althaher, Thikra Mohammed alblowi, Thammer Mohammed Ahmed and Balsam Taher Albondoqji

We also owe our gratitude to authority of Maternal and Children Hospital in Madina for facilitating our study by providing a suitable environment and encouraging us from the be-ginning up to this far. We are indebted and grateful to every patient who participated in this study. Finally, we are extending our thanks to everyone who has supported us to complete the research work directly or indirectly.

\section{Reverences: -}

1- Nursing, G., Nursing, G., Said, P., \& Mukarramah, M. A.-. (2012). No Title, 9(4), 4291-4299.

2- Lincetto, O., Mothebesoane-anoh, S., Gomez, P., \& Munjanja, S. (n.d.). Antenatal Care, 51-62.

3-Shafqat, T., Fayaz, S., Rahim, R., \& Saima, S. (2015). KNOWLEDGE AND AWARENESS REGARDING ANTENATAL CARE AND DELIVERY AMONG PREGNANT WOMEN, 23(2), 88-91.

4-Best, T., Lives, S., \& Progress, A. (n.d.). CALL TO ACTION : CONTINUED Frontline Health Workers : No Health Workers, No Health.

5-Bank, T. W. (2013). Trends in Maternal Mortality: 1990 to 2013.

FACTORS INFLUENCING ATTENDANCE TO ANTENATAL CARE SERVICES IN. (2015).

6-Onoh R, Umeora O, Agwu U, Ezegwui H, Ezeonu P, Onyebuchi A. Pattern and Determinants of Antenatal Booking at Abakaliki Southeast Nigeria. Annals of Medical and Health Sciences Research. 2012;2(2):169-175. doi:10.4103/2141-9248.105666.

7-Issue, S. (2012). Assessment of pregnant w omen's knowledge and practices concerning prenatal care who attend primary health care centers in Baghdad City, 25, 1-10.

8-Sheet, F., \& Facts, Q. (2015). FACT SHEET GOAL 5 : Improve maternal health, (September 2008), 2005-2006.

9-Nigenda, G., Langer, A., Kuchaisit, C., Romero, M., Rojas, G., Al-osimy, M., ... Al-, Y. (2003). Womens ' opinions on antenatal care in developing countries: results of a study in Cuba, Thailand, Saudi Arabia and Argentina, 12, 1-12.

10-Habib, F., \& Hanafi, M. I. (2011). Antenatal care in primary health care centres in Medina, Saudi Arabia, 2009 : a cross-sectional study, 17(3), 196-202.

11-Sadiq, N., Waheed, Q., Hussain, M., Rana, A. T., Yousaf, Z., Chaudry, Z., ... Iqbal, S. (n.d.). Students ' Corner Short Communication Factors affecting the utilization of antenatal care among women of reproductive age in Nurpur Shahan, 616-618.

12-Anjum F, Noor N, Bano S.To Asses the Knowledge of Women in Regards to Antenatal Care.Med Forum 2015;26(2): 23-26.

13-Otaiby, T. Al, Jradi, H., \& Bawazir, A. (2013). Women 's Health Care Antenatal Education: An Assessment of Pregnant Women Knowledge and Preferences in Saudi Arabia, 2(4), 2-6. http://doi.org/10.4172/2167-0420.1000139 14. AbouZahr, Carla. "Safe motherhood: a brief history of the global movement 1947-2002." British Medical Bulletin 67.1 (2003): 13-25.

15. Fosu, Gabriel B. "Childhood morbidity and health services utilization: cross-national comparisons of userrelated factors from DHS data." Social science \& medicine 38.9 (1994): 1209-1220.

16. Costello, Michael A., Lauro C. Lleno, and Eric R. Jensen. Determinants of two major early-childhood diseases and their treatment in the Philippines: Findings from the 1993 National Demographic Survey. East-West Center, Program on Population, 1996.

17. Chaaya, M., et al. "Knowledge, attitudes, and practices of argileh (water pipe or hubble-bubble) and cigarette smoking among pregnant women in Lebanon."Addictive behaviors 29.9 (2004): 1821-1831.

18. Awan, Mahe Munir, Muhammad Aftab Akbar, and Misbahul Islam Khan. "A study of anemia in pregnant women of railway colony, Multan." Pak J Med Res43.1 (2004): 11-4.

19. Javali, Rudramma, Appasaheb Wantamutte, and M. D. Mallapur. "Socio-demographic factors influencing utilization of Antenatal Health Care Services in a rural area-A cross sectional study." (2014).

20. Roy, Manas P., et al. "Determinants of utilization of antenatal care services in rural Lucknow, India." Journal of family medicine and primary care 2.1 (2013): 55 . 
21. Gupta, Rajiv Kumar, et al. "Knowledge regarding antenatal care services, its utilization, and delivery practices in mothers (aged 15-49 years) in a rural area of North India." Tropical Journal of Medical Research 18.2 (2015): 89.

22. Berhe, Kalayou K., et al. "Assessment of antenatal care utilization and its associated factors among 15 to 49 years of age women in Ayder Kebelle, Mekelle City 2012/2013; a cross sectional study." American Journal of Advanced Drug Delivery 2.1 (2014): 62-75.

23.Mastaneh, Zahra, and Lotfollah Mouseli. "Patients awareness of their rights: insight from a developing country." International journal of health policy and management 1 (2013).

24. Laishram, Jalina, et al. "Knowledge and practice of ante-natal care in an urban area." (2013).

25. Niroula, B. "Use of Health Service in Hill Village in Central Nepal." Health Transition Review 4.2 (1994): 15166.

26.Rahman, M., et al. "Determinants of antenatal care seeking behaviors in Bangladesh. ICDDR, B: Center for Health and Population Research." Reproductive Health in Rural Bangladesh 1 (1997): 86-104.

27.Sanjel, S., R. H. Ghimire, and K. Pun. "Antenatal care practices in Tamang community of hilly area in central Nepal." Kathmandu University Medical Journal 9.2 (2012): 57-61. 